Pedagogía y Saberes $n .^{\circ} 54$

Universidad Pedagógica Nacional

Facultad de Educación. 2021. pp. 69-84

\title{
Los presupuestos filosóficos en la Didáctica magna de Juan Amós Comenio -Comenio, 350 años-
}

The Philosophical Presuppositions in the Great Didactic of John Amos Comenius -Comenius, 350 Years-

Os pressupostos filosóficos da Didática Magna de João Amos Comenius -Comenius, 350 anos-

Germán Vargas Guillén*

Para citar este artículo

Vargas, G. (2021). Los presupuestos filosóficos en la Didáctica magna de Juan Amós Comenio —Comenio, 350 años-. Pedagogía y Saberes, (54). https://doi.org/10.17227/pys.num54-11525

* Profesor titular de la Universidad Pedagógica Nacional.

Correo electrónico gevargas@pedagogica.edu.co. Código Orcid: https://orcid.org/0000-0001-6156-799X 


\section{Resumen}

En este estudio se realiza una aproximación exegética a la obra clásica titulada Didáctica magna para auscultar los presupuestos filosóficos de la misma. En buena cuenta las siguientes reflexiones tienen como guía el punto de vista de Jan Patočka, un fenomenólogo que se acercó a la obra del padre de la pedagogía con la siguiente pregunta: ¿cómo entiende Comenio el mundo de la vida? De esta pregunta emergió una idea en la cual se circunscribe este estudio, a saber, en el pensamiento de Comenio está ínsita la idea fuerte de la existencia como estructura de los procesos de formación. Ahora bien, dentro del mundo de la vida el sujeto que entra en formación se descubre como sujeto del mundo. Desde luego, como sujeto advierte, eo ipso, que vive con otros —en intersubjetividad-. Y es en este punto en donde la formación exige no solo una idea de la naturaleza, del mundo, del orden de uno y otro. Por igual, exige método. Comenio idealiza el orden de la naturaleza y la concibe como modelo de y para la formación. Así, entonces, asume una suerte de continuidad entre la armonía del mundo y la armonía del alma, que puede ser alcanzada mediante la formación. Siguiendo muy de cerca el texto de Comenio se quiere hacer presente las anteriores consideraciones.

\section{Palabras clave}

método; didáctica; aprendizaje; enseñanza; efecto

\section{Abstract}

In this study an exegetical approach is made to the classic work entitled The great didactic to examine its philosophical presuppositions. In good account, the following reflections are guided by the point of view of Jan Patočka, a phenomenologist who approached the work of the father of pedagogy with the following question: how does Comenius understand the world of life? From this question an idea emerged in which this study is circumscribed, namely, in the thought of Comenius the strong idea of existence as a structure of formation processes is embedded. Now, within the world of life the subject who enters training is discovered as the subject of the world. Of course, as a subject he realizes, eo ipso, that he lives with others -in intersubjectivity-. And it is at this point where training requires not exclusively an idea of nature, of the world, of the order of one and the other. Equally, it demands method. Comenius idealizes the order of nature and conceives it as a model of and for formation. Thus, then, it assumes a kind of continuity between the harmony of the world and the harmony of the soul, which can be achieved through training. We want to make the above considerations present following closely the text of Comenius.

\section{Keywords}

method; didactics; learning; teaching; effect

\section{Resumo}

Neste estudo, uma abordagem exegética é feita à obra clássica intitulada Didática Magna, para examinar seus pressupostos filosóficos. A bem dizer, as seguintes reflexões são orientadas pelo ponto de vista de Jan Patočka, fenomenólogo que abordou a obra do pai da pedagogia com a seguinte questão: como Comenius entende o mundo da vida? Desta questão emergiu uma ideia à qual este estudo se circunscreve, a saber, no pensamento de Comenius está inserida a ideia forte da existência como estrutura de processos de formação. Agora, no mundo da vida, o sujeito que entra no treinamento é descoberto como sujeito do mundo. Claro que, como sujeito, ele se dá conta, eo ipso, de que convive com os outros —na intersubjetividade-. E é neste ponto que o treinamento requer não apenas uma ideia da natureza, do mundo, da ordem de um e de outro. Da mesma forma, exige método. Comenius idealiza a ordem da natureza e a concebe como modelo de e para a formação. Assim, então, assume uma espécie de continuidade entre a harmonia do mundo e a harmonia da alma, que pode ser alcançada por meio do treinamento. Seguindo de perto o texto de Comenius, queremos apresentar as considerações acima.

\section{Palavras-chave}

método; didática; aprendizagem; ensino; efeito 


\section{Consideraciones previas}

Comenio ha sido materia de estudio dentro de la tradición fenomenológica. En especial, ha sido Jan Patočka quien ha llevado a sus máximas consecuencias la lectura de la obra del Padre de la pedagogía y quien ha auscultado con mayor detalle las fuentes e influencias que hacen presencia en su pensamiento. Patočka lleva a ver cómo en el pensamiento de Comenio está ínsita la idea fuerte de la existencia -y de los movimientos de la existencia: acogida, defensa y verdad (Schifferová, 2014) - como estructura de los procesos de formación.

Este estudio, en buena cuenta bajo la guía del punto de vista de Patočka, es una aproximación exegética que sigue literalmente el texto de la Didáctica magna con la pregunta hermenéutica: ¿cómo entiende Comenio el mundo de la vida? Bien es cierto que, también en este punto, se puede seguir a Patočka: el mundo natural — que en filosofía parece haber sido instaurado por R. Avenarius (Patočka, 2016) - es el mundo en el cual, sin más, vivimos; es, se puede decir, el de la cotidianidad. En este mundo natural, no se nos exige, y en muchos casos, tampoco nos lo exigimos nosotros mismos, poner en cuestión el sistema de valideces; antes bien, los sistemas de valideces son asumidos y, en cierto modo, repetidos acríticamente.

Sin embargo, hay un momento en que el mundo natural es puesto en cuestión. Ahí, con preguntas que van desde el orden de la existencia hasta las que interpelan por lo que hay desde el punto de vista de las ciencias o por el sentido de la historia desde el punto de vista político: emerge el mundo de la vida (Patočka, 2016). En este, el ser humano se descubre sujeto del mundo. Desde luego, como sujeto advierte, eo ipso, que vive con otros -en intersubjetividad-.

Patočka, al igual que Eugen Fink - compañero y amigo de Patočka, en su amplio trayecto intelectual-, concibe que la filosofía de la educación es, sin más, una antropología (Schifferová, 2014): ¿cómo se entiende lo humano, cómo se llega a concebir y a formar en lo invariante o esencialmente humano? Es la cuestión que guía esta disciplina. Siguiendo a Comenio, esta antropología está orientada por el sino de que cada quien ha de alcanzar en su propia persona la plenitud de lo humano, su esencia. Y esta tiene por modelo, para Comenio, acaso como en eco de la mística de Meister Eckhart, a Dios; y, como en el modelo místico, la formación es la vía para alcanzar la unio mystica. Desde luego, si se da tal enlace es, para decirlo con Patočka, porque se logra el cuidado del alma. Y este implica, en la perspectiva de Comenio, el referente tanto del pecado como del don; si por el pecado se descubre que la persona puede volverse contra Dios, contra el prójimo y contra sí mismo, en cambio, por el don la persona descubre cómo tener y cultivar amor a Dios, piedad hacia el prójimo y cuidado de sí mismo.

Ahora bien, la formación exige no solo una idea de la naturaleza, del mundo, del orden de uno y otro; por igual, exige método. Comenio idealiza el orden de la naturaleza y la concibe como modelo de formación y para ella. Así, entonces, asume una suerte de continuidad entre la armonía del mundo y la armonía del alma, que puede ser alcanzada mediante la formación. De ahí que también se pueda hablar de la herencia barroca que gravita en su pensamiento.

Con todo, en el centro de la obra de Comenio lo que prima - como en muchos filósofos modernos- es la idea del método. Este se requiere para poder dar con el conocimiento del orden del mundo, para poder poner en funcionamiento cualquier proyecto, para restaurar cualquier caída o ruptura del mismo orden. Comenio hace una doble operación con respecto al método: lo deriva del orden natural del mundo, pero lo transmuta, o idealiza, como guía para la formación en los procesos pedagógicos.

Comenio es un reformador; no un reformado. Bien es cierto que le anteceden tanto Hus como Lutero, pilares de la Reforma. Pero, en pedagogía, de comienzo a fin el moravo no solo se concibe, sino que obra como un reformador de los ideales de formación, de las instituciones escolares, del pénsum y el currículo, de los métodos pedagógicos, de los dispositivos e instrumentos. Lo que implica que lo sea es, de fondo, que sabe que la pedagogía es el camino para lograr efectos de formación; y, si alguna validez tiene hablar de los propósitos, es solo porque de estos se establecen tanto su sentido como sus efectos en la experiencia.

Lo que queda del legado de Comenio, por supuesto, también es un acervo en los ámbitos sobre los cuales recayó su reforma pedagógica; en lo que implicó, para su momento y para la tradición que funda. Y, no obstante, si se mira el sentido de la configuración de la pedagogía como disciplina, ante todo, lo que queda como herencia es la actitud pedagógica entendida como una actitud de reforma: de los ideales, de las instituciones, de las prácticas. Solo que en el centro de esta tarea de reforma está, desde entonces e indefinidamente, como eje articulador el cuidado del alma.

El cuidado del alma es un índice, sí, psicológico, pero igualmente filosófico. Recordémoslo, desde Platón se habla del filósofo como médico del alma (Patočka, 2016). Solo que si del cuidado del alma se quiere hacer un proyecto político, entonces la pedagogía es, en sí, condición de posibilidad. Patočka reconstruyó cómo Sócrates había visto en la polis el lugar del cuidado del 
alma (Patočka, 2016): en ella no solo se abre el campo o el espacio de la libertad que libera de la atadura al lar, a la labor; allí se tiene, con su emergencia, un campo donde se despliega la libertad; en ella todo se delibera, es el suelo natal del pólemos. Por eso la política funda la filosofía, porque esta, ante la polis y la libertad en despliegue, es la exigencia del examen reflexivo de lo preferible, de lo virtuoso, de la areté. Por supuesto, frente a cualquier punto de vista filosófico se erige otro, el pólemos sigue su camino; este camino es, sin más, al que se puede llamar: historia.

La pedagogía es, prácticamente - bien que fundada filosófica o reflexivamente-, la vía de y para el cuidado del alma. Esto se hace con y por una reforma incesante, en pro de los ideales más altos que pueden llevar al sentido más alto y a la evidencia más plena de una humanidad auténtica. Patočka asume que esto es un acontecimiento existencial que se exhibe como responsabilidad. Nuestra tesis es que se trata de un efecto de corresponsabilidad que se vive en la plena expresión de la intersubjetividad.

La corresponsabilidad como experiencia intersubjetiva en el mundo de la vida no solo demanda que cada quien, existenciariamente, se haga cargo de lo que le concierne; también es una actitud de reclamo y de exigencia, en todo caso política, de que cada quien haga lo propio. Hoy, más que nunca, sabemos que los derechos al medio ambiente sano, al respeto de las diferencias individuales, a la información, por mencionar solo unos casos, no son solo materia de la responsabilidad individualmente considerada, sino de la corresponsabilidad intersubjetivamente demandada. Cuidar las selvas, la Amazonía; respetar en cada gesto los derechos de los niños, o albergar e incluir las diferencias no es asunto que se reduzca a las acciones individuales, aunque también las exige; es asunto de un reclamo infinito de justicia que funda la respuesta en la corresponsabilidad.

\section{Introducción}

Comenio nació en 1592 en la localidad morava Komňa; de esta deriva la voz o el gentilicio Komenský, que luego se latinizó como Comenius y llega al castellano como Comenio. El apelativo Amós hunde sus raíces en la tradición veterotestamentaria. La familia se radicó en Nivnice. Fue moravo, como E. Husserl. ${ }^{1} \mathrm{Se}$

1 Esta relación con Husserl, con su origen y “tradición”, en parte, explica la serie de estudios de Jan Patočka sobre Comenio. Dos de estos estudios son: "O nový pohled na Komenského" [For a new view on Comenius] (1941) y "Philosophical basis for Comenian pedagogy" (1957). Véase a este respecto el escrito de Daniel Vojtech (1999) titulado Jan Patočka: On art and philosophy. doctoró en teología en la Universidad de Heidelberg; por entonces esta disciplina tocaba de manera explícita los temas de la naturaleza - como presupuesto y paradigma para el tratamiento de los asuntos en su interior-. Su obra titulada Didáctica magna fue redactada originalmente en checo, entre los años de 1627 y 1630; el mismo autor preparó su versión en latín (no se cuenta aquí con la datación exacta de esta traducción). La edición príncipe de las obras de Comenio es de 1650, hecha en Ámsterdam. ${ }^{3}$

Es más o menos sobreentendido que Juan Amós Comenio se considera el fundador de la didáctica como disciplina (sea que se considere independiente o no) y, subsidiariamente, teórico de la pedagogía, de la enseñanza y del aprendizaje. Nuestra aproximación, en este estudio, a la Didáctica magna no desconoce este acervo de valoraciones; sin embargo, se sitúa en otro marco de referencia. Tras la edición, en 2017 de sus obras filosóficas (en checo) (Komenský, 2017), se puede ver más patentemente qué formulaciones hizo en el orden de la metafísica y de la teoría del conocimiento.

\section{Sabiduría: conocimiento y razón}

Comenio recuerda la sentencia de Pítaco, uno de los siete sabios de Grecia (junto a Tales, Solón, Bías, Quilón, Cléobulo y Periandro), que se hallaba ubicada en el frontispicio del Templo de Apolo en Delfos. Sentencias de los sabios eran comunes en muchos templos: Parménides nos lo recuerda e insinúa cómo servían de vía de acceso a la sabiduría de los "mortales". Comenio (1994) recuerda la frase: “Conócete a ti mismo!” para mostrar que la sabiduría o el conocimiento -aquí no interesa establecer si hay o no diferencia entre una y otro- tienen que ser investigados. La sentencia es una formulación primera o primaria de un modo de relacionarse con el conocimiento: es la investigación y su resultado (saber, conocimiento), la que permite que se opere un enlace, hipóstasis, entre la naturaleza humana y la naturaleza divina. De esta manera, la Didáctica magna parte de la aceptación de la inscripción délfica: "conócete a ti mismo", insignia de la filosofía griega. Este lema es tomado como una verdad clara y distinta que descendió del cielo para que fuera asumida por los seres humanos y así lograran alcanzar el fin superior. Este último es dictado por la razón dado que los humanos son seres superiores

2 Coincidente con la preparación de las Reglas para la dirección del espíritu (1628) de Descartes, con quien se encontró en la corte de la reina Cristina en Suecia.

3 En esta lectura se usa como referente documental Comenio, J. A. (1994). 
y tienen como objetivo dominar a todas las demás criaturas, dado que estamos dotados de "esencia, vida y sentido" (p. 1).

Si por algo se caracteriza la "misión del formador" es por hacer consciente de la "dignidad y excelencia" (Comenio, 1994, p. 1) de la naturaleza divina y de cómo ella tiene en el conocimiento -en la investigaciónuna vía para hallar todos sus medios, para conseguir "esta dignidad y excelencia" (p.1). Son los "dictados de la razón los que - por la investigación - llevan a comprender que el hombre es "necesariamente destinado a un fin superior" (p. 2). Pero, en todo caso, "debemos suponer que ha de existir algo donde esta vida intelectiva alcance su mayor desarrollo" (p. 2). En resultas, así se tenga un potencial para llegar a más altos grados de conocimiento — si así se puede decir-, este despliegue no está determinado naturalmente; antes bien, exige cultivo. Este, a su vez, requiere la voluntad que conduce a que las capacidades se apliquen a ciertos objetos y a apartarse de otros.

Según este enfoque, el conocimiento es un proceso que se incrementa por grados hasta elevarse a lo más alto. De este modo, "recibe constantemente cada vez más y más luz hasta la misma muerte" (p. 3). ${ }^{4}$ Sin embargo, nuestro último fin no es alcanzar la muerte, sino tener una "vida sempiterna" (p. 1). Este tipo de vida solo se logra desarrollando las potencias que tiene el ser humano en el alma. Estas potencias del alma exigen, para su despliegue, la aplicación de las fuerzas del cuerpo. Se debe recordar que este carácter progresivo solo tiene sentido si se acepta que se cuenta con una vida triple, a saber, vegetativa, animal e intelectiva. La primera está inmiscuida en nuestros cuerpos; la segunda está asociada a las operaciones del movimiento y de los sentidos; la tercera es espiritual y cercana a la vivencia de los ángeles. Estas tres vidas son progresivas y se deben desarrollar (deducatur) en términos de gradaciones, es decir, se van alcanzando grados superiores con el pasar de los años si, y solo si, se enseña lo útil y lo provechoso, ${ }^{5}$ lo cual se decide con el método de ir a las cosas mismas.

Investigar sobre nosotros mismos implica llegar a comprender que "todo se desarrolla en nosotros de manera tan gradual que un antecedente cualquiera despeje el camino al que sigue" (p. 5). Así, en consecuencia, se puede decir, analógicamente, que esta vida prepara para habitary es "instrumento adecuado para

4 Hay quienes han visto, incluso Piaget, en esta sentencia, la primera formulación de la educación permanente ( $c f$. Piaget, 1993).

5 Véase Mason (2001). En este libro se exponen los criterios distintivos de la ciencia empírica del siglo XVII, en especial se hace énfasis en la propuesta de Bacon. hacer fácil empleo en la siguiente vida" (p. 5). Son, visto el orden o la razón de las cosas adecuadamente conocidas, la secuencialidad y la progresividad dos principios que guían el trato con las cosas en símismas.

Aquello de lo cual se llega a saber es de este mundo visible; este hace las veces de "espejo del infinito Poder, Sabiduría y Bondad de Dios" (p. 5). De este mundo se puede, entonces, afirmar que es "nuestro Semillero, nuestro Refectorio, nuestra Escue$l a^{\prime \prime}$ (p. 5). Aquí aparece un dato relevante: un objeto de la sabiduría es el mundo; pero este hace las veces de "Camino, Marcha, Puerta, Esperanza" (p. 6) con respecto a esta vida humana en la que hemos de entendernos como "peregrinos, extranjeros, inquilinos que esperan otra ciudad" (p. 6). Entonces, no hay una naturaleza humana completa, sino que tiene que ser labrada o cultivada hasta llegar a descubrir y actuar en consecuencia con la presunción de que estamos destinados a la eternidad.

El saber es lo propio del hombre y este puede ostentar "la denominación de animal racional si se conocen las causas de todas las cosas" (p. 8). Así, entonces, la sabiduría humana es la que lleva a revelar, mediante el conocimiento,

dónde, cuándo, de qué modo y hasta qué punto se debe, prudentemente utilizar cada cosa; dónde, cómo, de qué modo y hasta dónde condescender con el cuerpo; dónde, cómo, de qué modo y hasta qué punto se debe servir al prójimo. (p. 8)

Se trata de hallar racionalmente la justa medida en que se puede utilizar y cuidar simultáneamente el mundo, los recursos naturales; de hallar la prudencia en la relación consigo mismo y con los demás. ${ }^{7}$

\section{La naturaleza}

Paradójicamente, como se ha visto, se presume la dación de dos naturalezas, a saber: la naturaleza humana y la naturaleza divina. Se puede plantear la presunción de esa doble dación o doble naturaleza puesto que el autor usa de manera explícita la palabra "hipóstasis". En un sentido, esta es, en el caso de Cristo, la doble naturaleza: plenamente humana $\mathrm{y}$, al mismo tiempo, plenamente divina; pero, si se trata de los demás humanos —excepción hecha de Cristo:

6 Salvo que se indique lo contrario, se mantienen los énfasis del original, en particular el uso de cursiva, versales y mayúscula inicial en ciertas palabras.

7 A su manera, hay una referencia a la triple dimensión del pecado: volverse contra Dios, volverse contra sí mismo, volverse contra el otro o el hermano; y, de retorno, de la bondad: amor a Dios, amor a sí mismo, amor al prójimo. 
plenamente humano; pero Dios mismo- en todos hay algo de divino. La criatura tiene en sí el rastro o la huella divina, del Creador. La distinción entre naturaleza humana y naturaleza divina puede ser, según el autor, puesta en cuestión: "Entendemos [...] nuestra primera y fundamental constitución, a la que hemos de volver" (p. 11). Desde esta perspectiva, se ofrece una manera de entender la hipóstasis naturaleza humana-naturaleza divina: es, como se ve, una sola naturaleza, pero aquella tiene en germen la potencialidad de reconciliarse con esta. Aquí no se entiende por qué creó el Creador; pero sí que la criatura haya querido alcanzar y llegar a tener el poder del Creador: el pecado original. ${ }^{8}$ En cierto modo es el doble efecto de la dialéctica entre transferencia y separación. Lo cierto es que la criatura ha caído, ha pecado, se ha vuelto en contra del Creador. Y, ¿cómo ha de salir de "la cárcel triste que labró el pecado"? Ha de salir al obrar, humanamente, de modo que lleve a descubrir a Dios como guía, como horizonte: "Entendemos [...] por voz de la naturaleza la universal providencia de Dios, o el influjo incesante de la bondad divina para obrar por completo en todas las cosas" (p. 11).

La divinidad o dimensión divina de la naturaleza hace un llamado (vocatio) a la dimensión humana, pero este tiene que ser descubierto y cultivado; no es una determinación, mucho menos una predeterminación. Este descubrimiento es logrado por la luz natural de la razón o con ella, pues "todo cuanto tiene existencia existe para algo y está dotado de los elementos necesarios para obtener su determinado fin" (Comenio, 1994, p. 11). Así, se trata de develar incluso el fin de lo que hay; no solo su constitución, su operación y su estructura.

\section{Naturaleza y conocimiento}

Es importante resaltar que para Comenio:

La esencia del alma está formada por tres potencias (que parecen hacer relación a la Trinidad increada): Entendimiento, Voluntad y Memoria. El entendimiento se aplica a estudiar las diferencias de las cosas (hasta por las menores notas). La voluntad tiene por oficio la opción de las cosas, para elegir las provechosas y reprobar las dañinas. La memoria guarda para usos futuros todo cuanto alguna vez fue objeto de la Voluntad y del Entendimiento y hace que el alma tenga presente su dependencia (que viene de Dios) y sus deberes; y en este aspecto se llama también Conciencia. Y para que estas facul-

8 Que también pueda ser un pecado originador, un pecado originante: es la idea que ofrece la doctrina de la felix culpa: " $O$ felix culpa quae talem et tantum meruit habere redemptorem". tades puedan ejercer diestramente sus funciones es necesario dotarlas claramente de aquellas cosas que iluminen el Entendimiento, dirijan la Voluntady estimulen la Conciencia, con lo que el entendimiento ahondará más, la voluntad elegirá sin error y la conciencia dirigirá todas las cosas hacia Dios. Del mismo modo que estas facultades (Entendimiento, Voluntad y Conciencia) no pueden separarse porque constituyen el alma misma, así tampoco pueden estar desunidos los tres adornos del alma: Erudición, Virtud y Piedad. (1994, p. 34)

Como ya se ha visto, lo que se conoce es el mundo, la naturaleza, pero es el ser humano quien llega a conocer; de ahí que "El hombre [...] teniendo su luminoso entendimiento a la manera de un espejo [...] reproduce las imágenes de todas las cosas" (p.12). Así, el entendimiento tiene una función especular y, progresivamente, de el emerge un método especulativo: se busca, al conocer, reflejar lo que es, lo que hay en el mundo. De la misma manera, "Comenio planteó un método práctico de aprender haciendo que los conocimientos se infiltraran e infundiesen suavemente, llevando al entendimiento la verdadera esencia de las cosas" (Gutiérrez, 2014, p. 103). Pero ¿cómo se ha de proceder (método)? En síntesis, se ha de ir de lo próximo a lo lejano, de lo conocido a lo desconocido: "Nuestro entendimiento [...] es ocupado por las cosas próximas, [...] también deja impresiones por las remotas [...], acomete las difíciles, indaga las ocultas, revela las desconocidas e intenta investigar las inexcrutables [sic]" (Comenio, 1994, p. 12). Se trata de un procedimiento procesual que ofrece el conocimiento de la naturaleza, el despliegue de los potenciales del conocimiento; de allí deviene un arraigo para la formación. Así, el entendimiento es como la semilla en germen. Se trata de aprender de la naturaleza, mantenerla por guía, pero es el mundo el que se conoce a partir de las semillas ${ }^{9}$ que ya están en el entendimiento: "todo cuanto el mundo encierra puede ser conocido por el hombre dotado de entendimiento y sentido" (p. 13); en todo este proceso de conocimiento está implicado el deseo natural de conocer. De este modo, "Los ejemplos de quienes se instruyen por sí mismos demuestran con evidencia que el hombre puede llegar a investigarlo todo con el auxilio de la Naturaleza" (p. 13). Dos cosas entonces quedan al descubierto: 1) que la guía del conocimiento está en la naturaleza visible que lleva o conduce a la invisible, de la criatura al Creador; 2) que el lema "iConócete a ti mismo!" tiene su raíz o fundamento en la experiencia (natural, vital). De ahí que se pueda afirmar: "[...] en el hombre se encuentran todas las cosas" (p. 13).

9 Como lo indica reiteradamente Descartes desde 1628. 
Pero el entendimiento, más que un depósito en el cual están contenidos unos conocimientos - se puede decir, innatos-, es un potencial ${ }^{10}$ que puede fijarlo todo siempre y cuando se conozca el artificio de enseñar y este es ilimitado. Así se puede afirmar que nuestro entendimiento es como un laboratorio de pensamientos [...], se deja modelar [...] recibe cuanto contiene el universo" (p. 14). Aquí se puede observar una aparente ambigüedad en el planteamiento de Comenio: el entendimiento lo contiene todo, pero se tiene que actualizar; esta actualización se logra mediante la experiencia. ${ }^{11}$

Para Comenio, entonces, ¿cómo se llega a reconocer? Mediante "sensaciones que impresionan mi vista, olfato, oído, gusto o tacto" que tienen la "manera de sellos que dejan impresa en mi cerebro la imagen de lo percibido" (p. 14). ¿Qué papel tiene aquí la memoria? Parece necesario que, para que el todo se actualice y opere, ahí sí como reconocido, se tiene que recurrir a la memoria como una facultad o un potencial que alberga lo puesto en escena, lo experienciado. La memoria es un profundo abismo; sin ella no puede obrar o desplegarse nuestro entendimiento que es parecidísimo al ojo o al espejo: refleja el mundo, lo representa; esta representación se ofrece como un conjunto, que queda asido como imágenes, en la memoria.

Para el conocimiento, para el entendimiento, aunque indirectamente - sin usar expresamente el término-, Comenio formula un innatismo. Esta formulación, en cambio, se expresa en relación con la moral; según sus palabras: "son innatos en el hombre ciertos gérmenes de virtudes" (p. 15).

Una suerte de paradoja queda ínsita en el punto de vista de Comenio: de un lado, asume que se ha de seguir a Aristóteles - o, al menos, lo que se le atribuye a este- según el dictum que reza que el alma del hombre se compara a "una tabla rasa, en la que nada hay escrito, pero en la que pueden escribirse muchas cosas" (p. 14); sin embargo, como ya se reconstruyó, exige que la experiencia sea una suerte de avivamiento o de reconocimiento de lo ínsito en ella. Como veremos, según el enfoque de Comenio, la posibilidad de recuperación o la salida del pecado requieren una participación de lo divino a la manera platónica, pero también de la experiencia a la manera aristotélica. Comenio filosóficamente se mueve entre Platón y Aristóteles: entre el mundo de las ideas y el mundo de la experiencia.

10 Quizá hoy se pudiera decir: una estructura. Comenio usa expresamente el término (p. 52; nota al margen).

11 En cierto modo, este punto de vista se puede leer como la interpretación fenomenológica - bajo otros supuestos- de la doctrina platónica: conocer es reconocer ( $c f$. Herrera, s.f.).

\section{Conocimiento de la naturaleza y de la gracia}

El entendimiento es natural; pero, claro, tiene que ser cultivado; este cultivo se ha de guiar por una suerte de orden natural: "todo lo que es moderado y ordenado es apacible y saludable para la Naturaleza, mientras que le resulta odioso lo nocivo y desmesurado y sin moderación" (p. 16). Conocer, aprender y enseñar, formar: son procesos que se surten si se logra dar con este orden. Ir contra el orden y la armonía de la naturaleza es el pecado: "El hombre, una vez corrompido por el pecado [...] puede reformarse por medios ciertos" (pp. 16-17). Si ha habido caída - pecado original-o recaída - siempre se puede obrar contra la armonía de la naturaleza-, puede haber reivindicación, todo puede ser "reparado y compuesto" pues: "la rueda principal en los movimientos del alma es la voluntad" (p. 16); es ella la que regula los deseos y los afectos mediante la razón; por ella es que se logran la armonía y las virtudes. Se puede ahora anticipar: la formación es un proceso de restauración de la naturaleza divina en la naturaleza humana. Esta restauración es lo que ofrece o puede ofrecer el resultado del esfuerzo tenaz de la voluntad que "encuentra dónde dirigir sus deseos [...] siempre [que] [...] conozca [la naturaleza] de un modo suficiente" (p. 17); en fin, que descubra el "solo instinto oculto en la Naturaleza" (p. 17).

¿Qué enseña la naturaleza? Comenio sigue a Cicerón cuando afirma que La primera maestra de la piedad es la naturaleza; en esa indagación de la naturaleza se encuentra el deseo natural de Dios, como sumo bien que se pierde o se ha perdido por el pecado; de este se puede salir, y se sale, cuando se elige que Dios ilumine con su palabra y su espíritu; es este el que excita continuamente. Así es como "el sentido humano" se abre "a la esperanza de volver a adquirir entendimiento" (p. 18) que lleve a "ser repuesto en la dignidad real" (p. 18). El entendimiento llega, entonces, a comprender el modelo que en último término se orienta a la gracia divina. Este es el enfoque que orienta el ejercicio del conocimiento para que produzca los frutos inmanentes a Dios; el entendimiento es un auxilio para ayudar a Dios - como aparece en la mística de Etty Hillesum-. Ahí se hace visible que "es natural al hombre ser sabio, honesto y santo dada la gracia y, que por la gracia del Espíritu Santo" (p. 18) se pueda superar el pecado. Esta gracia abre la posibilidad de revivir o de reactivar la divinidad en cada quien como vía para restaurar la alianza que se expresa como hipóstasis. 
Ahora se puede ver que, según la idea de la naturaleza de Comenio, esta "nos da las semillas de la ciencia, honestidad, religión y virtud, pero no proporciona las mismas Ciencia, Religión y Virtud; éstas se adquieren rogando, aprendiendo y practicando" (p. 20).

\section{Los procesos de conocimiento: experiencia y método}

Para Comenio "en el hombre [...] no puede darse ni la infinitud, ni la eternidad"; esto es, el "hombre" ha de recibir "la luz de la mente" puesto que "su conocimiento es experimental" (p. 20); ¿qué alcance tiene, aquí, el título conocimiento experimental? No es algo que se vaya a dejar establecido de una vez por todas; no obstante, al menos dos consideraciones deben hacerse: 1) el enfoque dado a la experiencia desde el punto de vista filosófico, en el ambiente intelectual de Comenio, estaba permeado por la perspectiva de Francis Bacon (Novum organum o indicaciones relativas a la interpretación de la naturaleza que data de 1620; la Didáctica magna, en su primera versión en checo, fue concluida en 1630); 2) en todo caso, frente a cualquier enfoque innatista - y también de la determinación o de la predeterminación- la experiencia es condición de posibilidad para que se lleve a cabo el despliegue de los potenciales (o, si se prefiere, de las potencias).

Así, "es un verdadero hombre" aquel que "haya aprendido", en sí y por sí mismo, "a formar su hombre" (p. 20); esto es, a formar en sí "todas aquellas cosas que [le] hacen [...] hombre" (p. 20). Es mediante la experiencia que se logra el aprendizaje; y este no solo es propio de los seres humanos, también de "los Animales" puesto que "si queremos utilizar su trabajo [...] hemos de procurar antes su aprendizaje [...] y de muy poco nos valdrán si no amaestramos a cada uno para su oficio" (p. 20). Claro que se debe llegar a hacer diferencias entre el aprendizaje que se logra por el amaestramiento y la educación o la formación del ser humano; pero aquí lo que importa señalar es que en animales humanos y no humanos aparece el potencial del aprendizaje. Y este solo se logra por la experiencia.

En particular "El hombre [...] al nacer [...] hay en él aptitud y poco a poco ha de ser enseñado" (p. 21). Si se quiere dar algún alcance a lo que viene, innato, con el nacimiento, es solo la aptitud — que bien podemos entender como un potencial, más que como potencia-. Se exige, entonces, descartar la hipótesis de que la naturaleza y su conocimiento pueda "existir por sí y ante sí sin preparación anterior" (p. 21). Antes bien, según el punto de vista de Comenio "es ley de todas las criaturas tener su principio en la nada y gradualmente irse elevando tanto en cuanto a su esencia en cuanto a sus acciones" (p. 21): no se podrá exceder el potencial que está ínsito en cada criatura, pero cada una de ellas se puede y debe "elevar" al máximo desenvolvimiento de su esencia.

Lo que obliga a aprenderlo todo, de nuevo, en y para cada criatura es "el estado de pecado" y en "nuestra mente [...] hay que excitarlo todo desde su fundamento" (p. 21). Un ejemplo vivo lo ofrecen las lenguas: a quien está movido por la ciencia le place "conversar con diversa gente, ya viva, ya muerta" (p. 21). Lo cierto es que nada de esto ciencia, o costumbre, o relación con las cosas, nace con nosotros. Así, a todos y para todo "es necesaria la cultura" (p. 22), el cultivo; e, incluso, "es necesaria la disciplina a los estúpidos para corregir su natural estupidez" (p. 22). Otro tanto será necesario para el cultivo de la disciplina y de quienes gozan de un "entendimiento despierto" puesto que "si no se ocupa en otras cosas útiles, buscará las inútiles, curiosas o perniciosas" (p. 22). Resultan entonces indesligables experiencia y aprendizaje.

Pero el aprendizaje, siempre anclado a la experiencia, exige la razón: para las bestias, la doma racional - como ha dado en llamarse a una aplicación del conductismo al entrenamiento de potros-; para los humanos, es imperativo que "hay que guiar [...] a la criatura racional [...] con la razón" (p. 23). Ahora se comprende la observación según la cual "a todos los que nacieron hombres les es precisa la enseñanza, porque es necesario que sean hombres" (p. 23).

En el proceso formativo, "El hombre se desarrolla por sí mismo en su figura humana [...]; pero no puede llegar a ser Animal racional, sabio, honesto y piadoso sin la previa plantación de los injertos de sabiduría, honestidad y piedad" (p. 24); es como si sobre una naturaleza - caída, por el pecado-se erigiera o levantará otra: sobre la natura se eleva la cultura; sobre una naturaleza precaria se levantará una naturaleza más plena. Ahí es donde se despliega la hipóstasis, la unión, el enlace: "el alma en nosotros vivientes se forma para el conocimiento y participación divina" (p. 24).

Para Comenio, el cerebro del hombre recibe "las imágenes de las cosas por medio de los sentidos" (p. 25); es decir, es la naturaleza la que se ejercita; esta es un soporte hilético o material del que no puede dejar de hacerse tanto un reconocimiento expreso como un recurso; este se logra mediante la experiencia. Esta ha de iniciar en "primera edad, durante la cual la imaginación es ágil y los dedos flexibles" (p. 25). Es la experiencia la que permite que esta situación inicial en que el hombre es inhábil, en los primeros años, se transmute cuando el ser humano tan sólo es apto para su formación. La formación, vía la experiencia, es entonces la que nos hace "aptos para el 
tiempo restante de la vida" (p. 26). No se trata solo de responder por el autocuidado, por la manutención; igualmente es un camino que lleva a que nos podamos hacer responsables de "los cuidados económicos y políticos" (p. 26).

Las experiencias, o cuidados, las ha de tener la persona tanto de aquellos a quienes corresponde naturalmente, los padres, pero también de

personas escogidas, notables por el conocimiento de las cosas y por la ponderación de las costumbres [...]. Y estos formadores de la juventud se llamarán Preceptores, Maestros, Profesores; y los lugares destinados a estas comunes enseñanzas: Escuelas,

Estudios literarios, Auditorios, Colegios, Gimnasios, Academias, etc. (p. 27)

Unos y otros conforman una comunidad educativa, en toda ciudad, pueblo o lugar; esto es lo que conviene a la República, de esta manera se conservan sus costumbres. Y, si no la tuvieren, en todo lugar es preciso que "se abra una escuela como educatorio común de la juventud"; así, por doquier "hemos de tener escuelas para la juventud" (p. 28). En ellas, en cuanto laboratorio de experiencias, se requiere "hacer una sola cosa sin distraerse" (p. 28), enfocarse temáticamente en los asuntos.

La experiencia educativa se caracteriza porque es compartida: "la enseñanza [...] es mucho mejor" cuando se "eduque la juventud reunida" (p. 28), pues los diversos miembros del grupo toman "el ejemplo y el impulso de los demás" (p. 28). Se trata, por tanto, de una experiencia intersubjetivamente fundada más en ejemplos que con reglas; de este modo en muchas conductas "verás imitar aun sin mandarlo" (p. 28) mucho de lo que se propone lograr en la experiencia.

Si se puede afirmar que las escuelas son precisas para la juventud es porque en ellas se ha de "avivar, depurar y multiplicar las luces de la sabiduría” (p. 29); es, entonces, porque en ellas se trata de un conjunto de experiencias, sí, pero estas han de ser significativas. La significación de las experiencias en la escuela va a radicar en la aplicación correcta del método de enseñanza que está guiado por la misma naturaleza. Incluso, Comenio afirma que el ser humano ya tuvo una escuela: el Paraíso, sin embargo, por el pecado original fue expulsado de ella; no obstante, solo a través de la creación de la escuela terrenal —que es el lugar por antonomasia para la educación cristiana- se puede restaurar o redimir la falta cometida. En este lugar hay profesores o educadores que son las personas encargadas de salvaguardar el alma de los estudiantes, de ahí que Comenio los compare con los ángeles (Borges y Vieira, 2018).

\section{La naturaleza humana es educable}

Se debe resaltar que:

No es obstáculo que haya algunos que parezcan por naturaleza idiotas y estúpidos. [...] esta cultura general de los espíritus [...] de naturaleza más tarda o perversa, hay que ayudarle más para que en lo posible se vea libre de su brutal estupidez. No hay que suponer que exista tanta negación del ingenio que no se pueda disminuir con la cultura. (Comenio, 1994, p. 30)

No existe ninguna razón por la que el sexo femenino [...] deba ser excluido en absoluto de los estudios científicos (ya se den en lengua latina, ya en idioma patrio). (p. 31)

A Comenio, por buenas razones, se lo considera primer promotor de la educación para todos; esto es, mujeres y hombres han de ser educados, "deben ser admitidos en las escuelas [...] todos por igual" (p. 30); y esto en razón de que "todos han nacido hombres [...] con el mismo fin principal[:] que sean hombres; [...] criaturas racionales, señores de las demás criaturas, imagen expresa de su creador [...] instruidos en las letras, la virtud y la religión" (p. 30). Así, quien iguala $\mathrm{y}$ ante quien se igualan todos los seres humanos, por su dignidad y divinidad, es Dios. Como, y por la gracia, él "quiere ser conocido, amado y alabado por todos" (p. 30). Pero esto no implica deshacer o desaparecer las diferencias individuales; antes bien, "no nos es conocido el fin a que destinó la Providencia a uno u otro $^{\prime 12}$ (p. 30). Este fin tendrá que ser descubierto por cada quien mediante su propio cultivo y por ello se exige la "cultura general de los espíritus" (p. 30) a sabiendas de que estos son variopintos por naturaleza. Se puede decir, por tanto, que hay ingenios: "agudos, ávidos y dúctiles" (p. 46). Para unos se requiere la paciencia, para otros, la escuela; para otros más, el gobierno acertado; el cuarto grupo exige la tolerancia benigna, el quinto, la prudencia y la paciencia extraordinarias; para el último, es necesario "corregir y extirpar la pertinacia" (p. 47).

12 Esta observación de Comenio no carece de dificultad. Como en "El espejo de los enigmas", de Borges: "nadie sabe qué ha venido a hacer a este mundo, ni cuál es su nombre, su infinito nombre en el registro de la luz"; pero la dificultad radica en que la Providencia parece determinar el destino de cada quien $\mathrm{y}$, no obstante, todo el proceso de conocimiento es un camino para que, intuitio personae, cada quien llegue a entender su camino, puerta, paso o peregrinar, esto es, su libertad. Entonces queda una suerte de cifra o de abigarramiento entre determinación y libertad en el punto de vista de Comenio. 
agudos, ávidos y dúctiles; agudos, pero lentos, aunque complacientes; agudos y ávidos, pero bruscos y tozudos; los que son simpáticos y ávidos de aprender, pero tardos y obtusos; los obtusos que al mismo tiempo son indolentes y perezoso [y finalmente] los obtusos y además de torcida índole, perdidos la mayor parte de las veces. (Comenio, 1994, p. 47)

No puede el formador claudicar ante las diferencias individuales. Antes bien, ha de acogerlas y convertir la dificultad en potencial, en posibilidad, en realización. Así,

formada de un modo legítimo esta universal instrucción de la juventud, a nadie han de faltarle ideas para pensar, desear, conseguir y obrar el bien; todos sabrán en qué hay que fijar todas las acciones y deseos de la vida, por qué caminos hay que andar y cómo proteger la posición de cada uno. (p. 32)

El caldo de cultivo de las diferencias individuales es la condición de posibilidad de la formación, de la educación, del aprendizaje, del conocimiento. ¿Qué tanto puede ser, entonces, homogenizado el proceso escolar? En principio, hay o puede haber un método general, para enseñar todo a todos - En las escuelas hay que enseñar todo a todos ${ }^{13}$-, pero este ha de ser variado o adaptado al amparo de los potenciales específicos e individuales. Así, no

hemos venido a este mundo, [...] sólo como espectadores, [...] también como actores, debemos ser enseñados e instruidos acerca de los fundamentos, razones y fines de las más principales cosas que existen y se crean. Y hay que atender a esto [...] para que [...] ocurra [...], durante nuestro paso por este mundo, que nos sea [...] [conocido y] [...] lo podamos juzgar modestamente y aplicarlo con prudencia [...] sin dañoso error. (p. 33)

Entonces se puede decir que los seres humanos no solo son educables, sino que para llegar a la plenitud de su humanidad se requiere la educación. De hecho, es por esta doble condición de posibilidad y necesidad de educación, que es ínsita a la naturaleza humana, que se puede decir "las escuelas" son "TALLERES DE LA HUMANIDAD, laborando para que los hombres se hagan verdaderamente HOMBREs"14 (p. 33); en cierto modo, sin la educación no se llega a experimentar y realizar la esencia de lo humano.

13 Según el autor, se requiere "escuelas en las que se enseñe todo a todos y totalmente" (p. 37).

14 En complemento observa el autor: "Llamo escuela, que perfectamente responde a su fin, a la que es un verdadero taller de hombres" (p. 37).
Esta naturaleza y esencia de lo humano hace visible que al "hombre [...] es preciso que se le enseñe" (p. 34); y esto desde "el triple fin"; a saber: "servir a Dios, a las criaturas y a nosotros mismos, y gozar de los bienes que provienen de Dios, de las criaturas y de Nosotros" (p. 34). A diferencia, y en complemento de la triple dimensión del pecado, hay una triple dimensión de la gracia que consiste en "servir a Dios, al prójimo y a nosotros mismos" (p. 34); o, en otros términos,

el hombre debe ser [...] prudente consigo mismo, [...] honesto y piadoso; [...] [en] las costumbres, [...] la ciencia y la piedad [...] emplearse con el prójimo, y en honor de Dios [...] la piedad, [...] las costumbres y la ciencia han de ejercitarse. (p. 34)

De esta manera, la educación en general y las escuelas en particular son talleres de piedad. De ahí que exprese su acuerdo con la exhortación de Lutero (1525) para que "en todas las ciudades, plazasy aldeas se creen escuelas para educar a toda la juventud de uno y otro sexo" y para que "se establezcan las escuelas con algún método, mediante el cual [...] se les atraiga con toda suerte de estímulos", y "experimenten los niños [...] placer en los estudios" (p. 37). Con desazón Comenio observa - cincuenta años más tarde de la proclama de Lutero- que "todavía no se han creado escuelas en las localidades pequeñas" (p. 38); que "las escuelas no son para todos, sino para unos pocos, los más ricos" (p. 38); que el método en las escuelas es tan duro, que estas son "tenidas por terror de los muchachos" (p. 38). Este método se puede considerar vicioso (p. 39) y -a la manera como argumentara Descartes ${ }^{15}$ - parece que "algún genio maligno, enemigo del género humano, ha introducido este método en las escuelas" (p. 39). Es, en resultas, a este extravío en o de las escuelas a lo que llama 'escolástica' (p. 39) y la caracteriza como años de "vaciedades [...] desdichadamente perdidos" (p. 39).

\section{Reformar las escuelas: el método y la enseñanza}

Lo que ofrece y promete Comenio es una organización de las escuelas que: 1) instruya "toda la juventud"; 2) haga "al hombre sabio, probo y santo" (p. 41); 3) prepare "antes de la vida adulta"; 4) proceda "leve y suavemente" (p. 41); 5) habilite al hombre para que "se guíe por su propia razón, no por la ajena"16 (p. 41),

15 "un cierto genio maligno, y además extremadamente poderoso y astuto, ha empeñado toda su habilidad para engañarme" (Descartes, 2008, p. 77).

16 Es esta sentencia, a su manera, una suerte de formulación del “Sapere aude!” kantiano. 
y 6) asegure que la "enseñanza sea fácil en extremo y nada fatigosa" (p. 41). Esto implica abandonar todas las "molestias y dificultades" que trae consigo "el método corriente"; una suerte de mortificación "tanto a maestros como a discípulos" (p. 43). En otras palabras, reformar las escuelas es cuestión de método.

¿Cómo es un método adecuado para la reforma de las escuelas? Aquel en el que "todas las cosas se dejan fácilmente ser llevadas adonde la Naturaleza las inclina; más aún, se precipitan con un cierto deleite que se torna en dolor si se trata de impedir" (p. 43); en las que tanto el conocer como el actuar sobre las cosas se hacen, naturalmente. En fin, en el que se da un complemento entre método e impulso; esto es, se complementa este con "una prudente dirección" (p. 43). El método es la vía para educar-reformar, toda vez que "un hombre [...] hace a otro hombre, si no hay corrupción" (p. 43). Esto se logra con o desde la misma naturaleza de cada quien, incluso, cabe decir, si bien "nuestras fuerzas y energías interiores enfermaron y se debilitaron grandemente" por "el pecado de origen" (p. 43), no por ello se puede decir que nuestras potencias o fuerzas se anularon o desaparecieron por él. En cierto modo, se puede decir que el método es un proceso de restauración. Con él se superan "los obstáculos en lo que hace relación al entendimiento siempre que se emplee la enseñanza adecuada" (p. 43); así, el hombre "ha de poder [...] ser instruido con facilidad en aquello a que su propia naturaleza [...] le llama o guía, [...] le empuja y arrebata" (p. 43). Si bien se puede decir que la naturaleza empuja hacia una(s) determinada(s) dirección(es), también se puede aseverar que la enseñanza, metódicamente considerada, allana el camino. Se pueden incluso indicar provisionalmente unas reglas del método: ubicar convenientemente, emplear "escaleras adecuadas" y "escalones bien dispuestos" (p. 44), "llegar a la más elevada altura por grados" (p. 44); se requiere que se pula y estimule la juventud, se motive el deseo de conocer, se evite perder en enfoque o atender "lo que provenga de otra dirección" (p. 45).

En términos metódicos, "el preceptor prepara al discípulo antes de sus lecciones haciéndole apetecer la cultura" y tornándolo "apto para ella" (p. 45). Pero todo esto ocurre recurriendo a "un solo y mismo método" para "instruir y formar a una juventud de una índole [...] diversa" (p. 47).

Primeramente: Todos los hombres han de ser encaminados a los mismos fines de Ciencia, Costumbres y Santidad. (p. 47)
En segundo lugar: Todos los hombres, sea cualquiera la diferencia que presenten en sus cualidades, tienen una única e igual naturaleza humana dotada de los mismos órganos. (p. 47)

Tercero: La expresada diversidad de cualidades no es sino exceso o defecto de la armonía natural. (p. 47)

Por último, es más fácil atender a los aludidos excesos y defectos del espíritu cuando son recientes. (p. 48)

[...] el maestro encomiende al que vea más despierto el cuidado de instruir a dos o tres más tardos; [...] atendiendo, desde luego, el Profesor para que todo se haga conforme a los dictados de la razón. (p. 48)

En cierto modo se puede afirmar que la enseñanza se puede algoritmizar. De lo que se trata, en todo caso, es que en cada paso se siga el orden de la naturaleza, que se busque elevar a su máxima expresión todos y cada uno de los potenciales de los sujetos, que de la rapidez del ingenio se saque tanto provecho como del ser o proceder tardo con este. Comenio es un reformador, no un reformado; su aporte es a la pedagogía lo que el de Lutero a la Iglesia, a la religión, a la teología. En otras palabras, Comenio es reformador porque sus ideas se asemejan a las propuestas de Lutero y Calvino, los precursores de la Reforma protestante de principios del siglo XVI. Recuérdese, por un lado, que Lutero en 1517 expuso en la iglesia de Todos los Santos (Wittenberg) sus 95 tesis mediante las cuales "niega la autoridad de la Iglesia de Roma y admite solo la Escritura" (Márquez, 2017, p. 2). ${ }^{17}$ Por otro lado, Calvino propuso una "transformación profunda de valores, ideas, acciones de vida religiosa, social y cultural que intentaron moldear la existencia comunitaria de acuerdo con la enseñanza del Evangelio" (Cervantes-Ortiz, 2009, p. 23). ${ }^{18}$

\section{El orden y la naturaleza}

Para Comenio, "cada criatura se contiene dentro de los límites conforme al mandato de la Naturaleza, y por este respeto del orden particular se conserva el orden de todo el Universo" (p. 49). Según su punto de vista, este es un orden inmutable. Del orden se puede decir que es una "destreza innata" que se revela como "número y medida" (p. 49); por igual se expresa en "el cuerpo del hombre" como "proporción de todos sus miembros" (p. 49) y esto hace posible un solo entendimiento que es suficiente para gobernar

17 Véase la Didáctica magna, capítulo xVIII, fundamento v.

18 Véase la Didáctica magna, capítulo xxıv. 
-al propio cuerpo - en función de su enlace "por vínculos perpetuos" (p. 49). Este gobierno de sí permite dar el paso a "gobernar a pueblos enteros" (p. 49). De ahí que el Rey o Emperador debe impulsar la educación; en especial, el jerarca debe estar sujeto al orden, pues es solamente mediante este que están "unidos todos por los vínculos de las leyes y de los deberes” (p. 50). También del orden tiene que valerse la máquina, tanto su construcción como su funcionamiento y, desde luego, su reparación; así mismo, es la estructura que debe guardar la guerra "y la aplicación de los elementos activos a los pasivos" (p. 50) de granaderos y bombardas. Este recurso al orden alcanza el arte tipográfico al "esculpir, fundir y pulimentar los tipos" (p. 50) y las embarcaciones, "frágil leño" (p. 50), que, al cabo, operan "por la ordenada disposición en la nave" (p. 50). Así, se puede llegar a afirmar que no hay "oculta fuerza, [...] sino el orden manifiesto" (p. 51); este ha de ser investigado para poder actuar con o sobre él, pues "todas las cosas dependen de un único orden" (p. 51). Si se investiga el orden y se obra con base en él se llega a la conclusión de que solo se "requiere [...] el arte de enseñar [...] una ingeniosa disposición del tiempo, los objetos y el método" (p. 51). De ahí que llegue a la formulación según la cual: "El orden que establezcamos para las escuelas debemos tomarlo de la naturaleza" (p. 52).

De lo que se trata es de "investigar sobre [...] el Método de enseñar y aprender" y para ello es imperativo procurar [...] remedios a los defectos naturales; ${ }^{19}$ y estos remedios "debemos buscarlos en [...] la misma Naturaleza" pues "el arte nada puede si no imita a la Naturaleza" (p. 52). ¿Cómo imitar la naturaleza? Hay ejemplos por doquier: al nadar los hombres imitan los peces, en busca de "ejecutar operaciones semejantes" (p. 52); en relación con los sonidos, a semejanza de la naturaleza, "se construyen las flautas, gaitas y los demás instrumentos" (p. 52); en materia de acueductos, dado que "el agua busca la igualdad de superficie", se usan mecanismos para que el agua suba y se distribuya: "Esto es [...] natural [...] está en la Naturaleza" (p. 52). En resumidas cuentas, con respecto a todo es posible operar hasta "conocer la razón de toda su estructura" (p. 53). Al investigar, esta es la función explícita del conocimiento: dar con la estructura, poder seguir su curso, intervenirlo cuando se aparte del orden natural para que retorne a ese curso, lle-

19 Orden, kosmos, se opone a caos. ¿Cómo tratar lo anómalo, lo monstruoso, etc.? Parece que la opción tomada por Comenio es la de encaminarse al orden. Esto implica llevarlo todo hacia él, acaso con pérdida de la diferencia, del diferendo, de monstruoso. varlo a su máxima exposición o realización..$^{20}$ De ahí que "la idea universal del arte aprender y de enseñar [...] debemos [...] tomarle de [...] las enseñanzas de la Naturaleza. Organizado cuidadosamente, tan suave y naturalmente se desarrollará lo artificial como suave y naturalmente fluye lo natural" (p. 53). En esta manera de plantear el asunto se puede comprender que la razón, el entendimiento, puestos en ejercicio, reconcilian la naturaleza humana con la naturaleza en general, y una y otra con la divina.

Sí, es un hecho: la vida humana es finita, está permeada por la finitud, pero justamente "tuvo a bien concedernos Dios el solo espacio de tiempo que estimó suficiente para que pudiéramos prepararnos a otra vida mejor" (p. 54). Pero, también esta vida está signada por la variedad de entes y de enseñanzas, con base en ellos, mediante las cuales "Dios quiso [...] que las cosas fuesen muchas, con el fin [...] de que hubiere mucho que nos ocupase, ejercitase e instruyese" (p. 54). También todo está sujeto al vértigo del curso del tiempo: Dios “Quiso que las cosas pasasen raudas" (p. 54); que nuestro conocimiento esté signado por la incertidumbre y que, el juicio de las cosas sea difícil.

Según esta doctrina, el hombre solo puede salvarse:

I. Con la prolongación de la vida, para que sea suficiente al camino emprendido.

II. La abreviación de las artes, para que correspondan a la duración de la vida.

III. La sujeción de las ocasiones, para que no se escapen inútilmente.

IV. La apertura del entendimiento, para que penetren las cosas con facilidad.

v. En lugar de la observación incierta, la determinación de un fundamento inmutable que no pueda engañar (p. 54). ${ }^{21}$

Se trata de un asunto de salvación, de encaminarse al Creador mediante el ejercicio de la investigación que, al cabo, da con la reconciliación. Todo esto vuelve

20 Como en la frase de Pablo (Rom. 8, 22-23): "sabemos que toda la creación gime a una, y a una está con dolores de parto hasta ahora; y no sólo ella, sino que también nosotros mismos, que tenemos las primicias del Espíritu, nosotros también gemimos dentro de nosotros mismos, esperando la adopción, la redención de nuestro cuerpo".

21 Aquí no está de más recordar las cuatro reglas en las cuales Descartes (1637) sintetiza el método (de 1628): no dar por cierto nada en la vida, dividir toda cuestión en sus elementos, recorrer una a una las cuestiones o elementos, y reunir o sintetizar los resultados. 
a mantener implícita la idea del orden en la naturaleza no humana, en la humana y en la divina como guía del ejercicio tanto de la investigación como del aprendizaje y de la enseñanza.

La investigación, para Comenio, tiene un valor en relación con la experiencia y con las consecuencias de esta. Así, entonces, cabe resaltar cómo, según sus palabras:

Vamos a intentar inquirir, valiéndonos de Naturaleza

\begin{tabular}{|c|c|}
\hline Los fundamentos & $\begin{array}{l}\text { de prolongar la vida para } \\
\text { aprender todo lo necesario. } \\
\text { de abreviar las artes para } \\
\text { aprender más de prisa. } \\
\text { de aprovechar las ocasiones } \\
\text { para aprender con certeza. } \\
\text { de afinar el juicio para apren- } \\
\text { der con solidez. (p. } 55 \text { ) }\end{array}$ \\
\hline
\end{tabular}

Según el punto de vista de Comenio, todo esto se puede mediante - usemos la expresión de Descartes- la "luz natural de la razón". Como queda visto, no es asunto de piedad, o al menos no lo es en primera instancia. Si se aísla todo presupuesto teológico, las observaciones valen por igual. Ahora de lo que se trata es de ver cómo se explicitan estos fundamentos, cómo se operacionalizan tanto para el conocimiento que se ejercita con la investigación como con el aprendizaje y con la enseñanza.

\section{La prolongación de la vida}

Comenio coincide con Séneca en la sentencia según la cual "No recibimos breve la vida, sino que la hacemos" (p. 56), y es la falta de cuidado "con lo que hacemos que se extinga antes de tiempo" (p. 56). Ahora bien, en lo que debe hacer especial hincapié cada quien es en que "cualquiera que sea la edad que alcance [...] es suficiente para preparar el refugio de la eternidad" (p. 57). También, coincidiendo con otra sentencia de Séneca, se puede decir: "No se trata de vivir mucho, sino de vivir bien"; esto es, "nuestra vida [...] Midámosla por las acciones, no por el tiempo" (p. 57). Si se preguntara "¿cuál es la mayor duración de la vida?" La respuesta es: "Vivir hasta la sabiduría" (p. 57). Visto todo lo anterior, al parecer solo hay "Dos remedios para [...] aplicar a las quejas sobre la brevedad de la vida" (p. 57), a saber, que: "I. El cuerpo se defienda de las enfermedades y de la muerte" y "II. Preparemos nuestro entendimiento para administrar sabiamente las cosas" (p. 57).

\section{En todo caso, se ha de advertir que}

nuestro cuerpo [...] es la morada del alma [...] organismo, sin el cual no podemos oír, ver, hablar ni hacer nada ni siquiera pensarlo. Porque como nada hay en el entendimiento que antes no haya estado en el sentido, la mente toma de los sentidos los materiales de sus pensamientos, y la operación de pensar no se verifica sino por la sensación interna, esto es, por la especulación de las imágenes abstraídas de las cosas. (p. 57)

Por esto "Estamos obligados a defender nuestro cuerpo de las enfermedades y peligros" (p. 57). El cuerpo humano no solo tiene, como organismo, facultad sensitiva, del orden de los sentidos; también goza de la facultad del entendimiento, del pensamiento y de la imaginativa con la cual se logra operar en el orden de la abstracción.

Comenio hace observaciones en torno a la dietética como condición de posibilidad para la preservación de la salud, pues el alimento debe ser moderado. Esta dimensión dietética se relaciona, por un lado, con la "transpiración y vegetación" (p. 58) y, por otro, con el descanso. En todo este proceso es necesario "que nada se haga con violencia, que es contraria a la naturaleza. En medio de los trabajos diarios hay que procurar algún respiro, conversación, juegos, recreos, música u otras cosas parecidas que distraen los sentidos externos e internos" (p. 58). Este planteamiento se puede traducir en tres principios: "nutrir su cuerpo con moderación, ejercitarle y dar ayuda a la naturaleza" (p. 59). Estas son "condiciones" que deben ser "guardadas con rigor" (p. 59). Esto, empero, se tiene que traducir en una "recta distribución del tiempo para el trabajo" (p. 14; nota marginal). Guardadas fielmente estas condiciones se ha de esperar un adecuado desarrollo; este es efecto de un proceso metódico: "el proceso que sigue nuestra mente para adquirir el conocimiento de las cosas" (p. 59); este procesualismo ha de conducir a la sentencia guía:

Aumenta un poco a lo poco y al poco añade un poquito.

Así en breve tiempo reunirás un gran montón. (p. 59)

Ahora bien, en aras del cuerpo y de su cuidado, se hace imperativo ver la distribución de las 24 horas del día. Estas han de ser

divididas en tres partes para el uso de la vida, ocho corresponden al sueño, otras tantas para los actos externos (cuidado de la salud, tomar los alimentos, vestirse y desnudarse, recreos honestos, conversaciones de amigos, etc.) y quedan otras ocho para los trabajos serios, que han de hacerse intensamente y 
sin desmayo. Semanalmente (dejando el séptimo día íntegro para el descanso) se tendrán cuarenta y ocho horas dedicadas al trabajo y al cabo de un año dos mil cuatrocientas noventa y cinco. (p. 59)

Es tan relevante el trabajo, que su dimensión productiva se tiene que ordenar a la relación con los otros, en los modos de la amistad, de la socialización. Para Comenio, se trata de que el trabajo tenga intensidad y se resuelva con criterios de rendimiento - que se pueden caracterizar bajo el criterio de la seriedad-. No obstante, el trabajo no es un hacer por el hacer, sino un hacer en medio de la vida y para la vida; esta es mucho más que trabajo y que rendimiento.

\section{Los fundamentos del método}

En el capítulo XVI Comenio se ocupa de los "Requisitos generales para aprender y enseñar. Esto es: de qué modo debemos enseñar y aprender con tal seguridad que necesariamente hayan de experimentarse los efectos". Con esto el autor expresa una fe incontestable en el método. Más aún, se puede hablar de Comenio, el Reformador de las escuelas - de la investigación, de la enseñanza y del aprendizaje- por el método o con este. Para ello es imperativo reconocer cómo "El incremento de las cosas naturales se efectúa por el método" (p. 61); el método alcanza por igual "lo artificial" (p. 61). Para esto es preciso que el "hombre [...] reciba en su corazón la semilla de las doctrinas" (p. 61). Entonces es posible hacer una restricción metodológica: "Sólo toca [...] a los que instruyen a la juventud el sembrar, el regar abundantemente las plantitas" (p. 61). Siguiendo la metáfora del cultivo, lo que se requiere en el orden del método es "cierto arte y pericia para sembrar y plantar" (p. 61). El método es un camino de prudencia en el cual se "obra con seguridad, conociendo qué, dónde, cuándo y cómo ha de operar o dejar de hacer"; de lo que se trata es de "prevenir lo fortuito" mediante el arte. Así, expresamente, lo que cabe decir del "método de enseñar" es que es un "arte de [...] plantación espiritual" que puede "establecerse sobre fundamento tan firme que se emplee de un modo seguro sin que pueda fallar" (p. 61). El fundamento del arte de enseñar consiste en "acomodar las operaciones [...] a la norma de las operaciones de la naturaleza" (p. 61). ¿Qué queda con el método en términos de sus fundamentos? Comenio sugiere nueve fundamentos, todos en orden a caracterizar cómo se ha de proceder metódicamente tanto al aprender como al enseñar, siempre bajo el supuesto de que la responsabilidad de la guía es del maestro o recae sobre este.
A manera de síntesis de la exposición precedente, se presentan estos nueve fundamentos. La presentación siguiente enfatiza en los recursos a las cosas mismas como referentes del aprendizaje y de la enseñanza, la triple relación que despliega uno y otro (consigo mismo, con la piedad y con los otros) y, finalmente, el hecho de que el alcance de la formación radica en sus efectos, esto es, la educación solo se justifica por los efectos de formación.

El fundamento 1 señala que "La naturaleza aprovecha el tiempo favorable" (p. 62). Lo que se indica bajo este supuesto es que en las escuelas es necesario utilizar "el tiempo adecuado para el desarrollo del entendimiento" y disponer "los ejercicios con tal cuidado que [...] se verifique [...] por sus pasos contados" (p. 62). La alusión al tiempo se refiere, en este texto, a las horas o momentos del día ("las horas de la mañana" [p. 63]) y de la vida ("debe empezarse en la primavera de la vida" (p. 63) en que es más eficiente el aprendizaje y la enseñanza. En orden al tiempo (el tiempo oportuno, el kairós), el "aprender debe escalonarse conforme a grados de edad" (p. 63).

El fundamento 2 lo dedica Comenio a estudiar cómo "La Naturaleza prepara la materia" (p. 63). En este sentido, las escuelas deben cuidar "de tener dispuestos para el uso sus instrumentos de trabajo: libros, tablas, modelos, ideas, etc." (p. 63); por su parte, los libros han de guardar "el orden natural de que preceda la materia y siga la forma" (p. 64). Esta manera de disponer la materia de la enseñanza permite entender que "es imposible ordenar sin poseer antes lo que debe ponerse en orden" (p. 64). Según esta perspectiva: "las cosas [...], las palabras [...] Deben presentarse juntamente unas y otras al entendimiento humano; pero en primer lugar las cosas, puesto que son el objeto, tanto del entendimiento como de la palabra" (p. 64). Por contera, "el método [...] requiere" que estén "dispuestos los libros y demás instrumentos" para que "se forme el entendimiento antes de la lengua", pues "ninguna lengua se aprenda por la gramática, sino mediante el uso de los autores adecuados", y es necesario que "las enseñanzas reales vayan antes de las orgánicas", que "los ejemplos precedan a las reglas" (p. 64).

El fundamento 3 muestra que "La naturaleza toma para sus operaciones los sujetos a propósito" (p. 64); esto es, "los que han de ser transformados en hombres no deben salir del taller antes de su total formación" (p. 65). Esto exige que "Todo el que en la escuela ingrese, tenga perseverancia" y que "Para cualquier estudio que haya de emprenderse hay que preparar el estudio de los discípulos". Si por algo se caracteriza el método es porque "Hay que despojar de impedimentos a los discípulos" (p. 65). 
El fundamento 4 establece que "La naturaleza no se confunde en sus obras, procede claramente en cada una de ellas" (p. 65) bajo el supuesto de que la naturaleza "efectúa cada cosa en su tiempo y lugar" (p. 66); así, en las escuelas debe evitarse "la confusión de enseñar a los discípulos muchas cosas a la vez" (p. 66): es como si se tratara del principio de demarcación en un enfoque positivista- o de un criterio de tematización - según la perspectiva fenomenológica-. No llevar a cabo el proceso bajo ese criterio perturba a los discípulos y, en cambio, es preciso operar bajo el lema de que "se ocupen en cada momento [...] de una cosa sola" (p. 66).

El fundamento 5 esclarece que "La Naturaleza comienza todas sus operaciones por lo más interno" (p. 66), esto es, se trata de ir a las cosas mismas; según Comenio:

\begin{abstract}
si el formador de la juventud actúa intensamente sobre la raíz del conocimiento, esto es, el entendimiento, con facilidad pasará el vigor a la estaquilla, la memoria, y aparecerán por fin las flores y los frutos, el uso expedito del idioma y el conocimiento de las cosas. (p. 67)
\end{abstract}

De lo que se trata es de "una diligente investigación de las cosas" (p. 67). Es a partir de ellas que "se debe abrir con suavidad la raíz y colocar los injertos de las doctrinas" (p. 67). Como reiteración, indica Comenio, que "Debe formarse primero el entendimiento de las cosas; después la memoria, y, por último, la lengua y las manos", esto es, "Debe tener en cuenta el Preceptor todos los medios de abrir el entendimiento y utilizarlos congruentemente" (p. 67).

El fundamento 6 estudia cómo "La naturaleza parte en la formación de todas sus cosas de lo más general y termina por lo más particular" (p. 67); en términos del método en la enseñanza, esto implica que en las escuelas "Se echen los cimientos de la erudición general desde el primer momento de su formación en la inteligencia de los niños que han de dedicarse a los estudios" (p. 68) y que en ellas

Cualquier idioma, ciencia o arte se enseñe primero por los más sencillos rudimentos para que tenga de ella total idea. Luego, [...] los preceptos y ejemplos. En tercer lugar, el sistema completo con las excepciones. Por último, los comentarios, si hay necesidad. El que se hace cargo del asunto desde el principio no tiene necesidad de comentarios. El mismo, tal vez, pueda comentar poco después. (p. 68)

El fundamento 7 observa que "La Naturaleza no da saltos, sino que procede gradualmente"; por ello,
El núcleo de los estudios debe distribuirse cuidadosamente en clases, a fin de que los primeros abran el camino a los posteriores y les den sus luces.

Hay que hacer una escrupulosa distribución del tiempo para que cada año, mes, día y hora tenga su particular ocupación.

Debe observarse estrictamente la extensión del tiempo y el trabajo para que nada se omita ni se trastorne nada. (p. 68)

Comenio insiste tanto en la gradualidad como en la procesualidad del conocimiento: investigación, aprendizaje y enseñanza. Pero estos principios implican una implementación didáctica en términos de la relación con el tiempo para que se proceda paso a paso, por una parte; pero, por otra, la didáctica exige que se obre una suerte de acumulación o incremento para dar con el sedimento - la configuración del estrato de la pasividad- del conocimiento. Es, entonces, un paso incesante de actividad a pasividad, ${ }^{22} \mathrm{y}$ viceversa.

Según el fundamento 8 "La Naturaleza así que comienza no cesa hasta terminar" (p. 70). Para Comenio, es fácil olvidar o ignorar esta enseñanza de la naturaleza; entre los humanos es fácil ir contra este orden. Entonces, para volver a ese aprendizaje y a ese orden natural, en el proceso educativo:

Al que haya de ir a la escuela reténgasele en ella hasta que se convierta en hombre erudito, de buenas costumbres y religioso.

La escuela debe estar en lugar tranquilo, separado de las turbas y barullos.

Lo que, según esté establecido, haya que hacer, hágase sin interrupción alguna.

No deben otorgarse a nadie salidas ni vagancias. (p. 70)

Lo que Comenio reclama es que la educación, en particular las escuelas, se orienten a inculcar e incluso a exigir lo que se puede caracterizar como disciplina. Los límites entre el método y la disciplina no solo son borrosos y confusos, sino que imponen señalar el alcance de la enseñanza: generar efectos - como reza el título de este capítulo en estudio-. Al final, como quiera que sea, la educación se caracteriza por lograr efectos de formación.

El fundamento 9 dilucida cómo "La Naturaleza evita diligentemente lo contrario y nocivo" (p. 71).

22 En síntesis, pasividad: saber que no sabemos que sabemos; actividad: consideración atenta, temática, reflexiva ( $c f$. Vargas, 2019, p. 10; pp. 49-50). 
Que los discípulos no tengan abundancia de libros, a no ser los de su clase.

Que los libros referidos estén de tal modo preparados que no pueda aprenderse en ellos sino sabiduría, piedad y buenas costumbres.

No deben tolerarse compañías disolutas ni en las escuelas ni cerca de ellas. (p. 71)

Comenio insiste en una relación triple: con el deseo, por limitación; con los contenidos, que lleven al recto entendimiento; con los compañeros, para que sus relaciones sean fecundas y productivas. Es la triple relación del pecado, transmutado en gracia, en don, en salvación: consigo mismo (el deseo, el ardor del bien), con los demás (las relaciones de rigor, disciplina y cooperación), con Dios (el elevamiento a Él, con base en la sabiduría, la piedad y las buenas costumbres).

\section{Referencias}

Borges, T. y Vieira, P. (2018). Comenius e o poder instructivo dos anjos. Revista Brasileira de História da Educação, $18,1-25$.

Cervantes-Ortiz, L. (2009). Juan Calvino su vida y obra a 500 años de su nacimiento. Editorial CLIE.

Comenio, J. A. (1994). Didáctica magna [S. López, trad.]. Porrúa.

Descartes. R. (2008). Meditaciones acerca de la filosofía primera [J. A. Díaz. trad.]. Universidad Nacional de Colombia.
Gutiérrez, A. M. (2014). Juan Amós Comenio: concepto y naturaleza de la pedagogía. Quipuramayoc, 43, 101-104.

Herrera, D. (s.f.). La doctrina platónica de las ideas. Universidad del Valle.

Komenský, J. A. (2017). Spisy o pruvní filosofi. Oikoymenh.

Márquez, C. (2017). Lutero y el inicio de la Reforma protestante. Revista de la Universidad de Cantabria, 21, 1-14.

Mason, S. (2001). Historia de las ciencias. 2. La revolución científica de los siglos XVI y XVII. Alianza.

Patočka, J. (1941). 0 nový pohled na Komenského/ For a new view on Comenius. Kritický mesícník, 4(5-6), 222.

Patočka, J. (1957). Philosophical Basis for Comenian Pedagogy. Ceskoslovenska Akademie ved, Pedagogica, (2), 137-177.

Patočka, J. (2016). Ensayos heréticos de filosofía de la historia [I. Ortega trad.]. Ed. Encuentro.

Piaget, J. (1993). Jan Amos Comenius. International Bureau of Education, XXIII (1/2), 173-196.

Schifferová, V. (2014). Jan Amos Komenský - portrét filozofa. En V. Leško, V. Schifferová, R. Stojka y P. Tholt (eds.). Patočka a novoveká filozofia. Košice: Univerzita Pavla Jozefa Šafárika v Košiciach (pp. 105-128). Pavol Jozef Šafárik University.

Vargas, G. (2019). Fenomenología y performance. Aula de Humanidades.

Vojtech, D. (1999). Jan Patocka: On Art and Philosophy. A Decade of Transformation, IWM Junior Visiting Fellows Conferences, 8(1). 